\title{
OPEN Origin of light instability in amorphous IGZO thin-film transistors and its suppression
}

\begin{abstract}
Mallory Mativenga ${ }^{1 凶}$, Farjana Haque ${ }^{1}$, Mohammad Masum Billah ${ }^{1}$ \& Jae Gwang Um²
Radiating amorphous In-Ga-Zn-O (a-IGZO) thin-film transistors (TFTs) with deep ultraviolet light $(\lambda=175 \mathrm{~nm})$ is found to induce rigid negative threshold-voltage shift, as well as a subthreshold hump and an increase in subthreshold-voltage slope. These changes are attributed to the photo creation and ionization of oxygen vacancy states $\left(V_{0}\right)$, which are confined mainly to the top surface of the a-IGZO film (backchannel). Photoionization of these states generates free electrons and the transition from the neutral to the ionized $V_{O}$ is accompanied by lattice relaxation, which raises the energy of the ionized $V_{O}$. This and the possibility of atomic exchange with weakly bonded hydrogen leads to metastability of the ionized $\mathrm{V}_{\mathrm{O}}$, consistent with the rigid threshold-voltage shift and increase in subthreshold-voltage slope. The hump is thus a manifestation of the highly conductive backchannel and its formation can be suppressed by reduction of the a-IGZO film thickness or application of a back bias after radiation. These results support photo creation and ionization of $V_{O}$ as the main cause of light instability in a-IGZO TFTs and provide some insights on how to minimize the effect.
\end{abstract}

Light exposure has always been problematic for all thin-film transistors (TFTs) ${ }^{1-3}$ and amorphous-indium-gallium-zinc-oxide (a-IGZO) TFTs $^{4,5}$ are no exception. When combined with negative bias, near or above bandgap radiation of a-IGZO TFTs induces large negative threshold-voltage shift $\left(\Delta \mathrm{V}_{\mathrm{TH}}\right)$, and numerous studies have been done to investigate the origin of this negative bias under illumination stress (NBIS) instability ${ }^{6-15}$. To date, there is no mechanism that has been universally agreed-upon and several mechanisms have been suggested to explain the negative $\Delta \mathrm{V}_{\mathrm{TH}}$, including trapping of photogenerated holes ${ }^{8}$ and/or creation of oxygen vacancy $\left(\mathrm{V}_{\mathrm{O}}\right)$-related defects ${ }^{10-15}$.

Identifying the origin of the NBIS instability and reducing its effect is of paramount importance, given that the largest application for a-IGZO TFTs are displays, and the TFTs operate in the presence of light inside the displays. Although several methods to reduce defects in the a-IGZO films such as film thickness reduction ${ }^{9}$, treatments, or annealing in highly oxidative environments ${ }^{12,16-20}$ have been proposed to reduce the effect of NBIS, light shields have been the most widely used ${ }^{21}$. However, alternatives to light shields are still required in applications forbidding the use of opaque metal layers, such as transparent displays used in Heads Up Displays (HUDs) or smart glasses. As negative bias applied in the absence of light is known to cause negligible changes in the performance of the a-IGZO TFTs ${ }^{6,8}$, light is thus the major source of the NBIS instability.

In this study, we comprehensively investigate the effects of light radiation on a-IGZO TFTs in the absence of any electrical bias. We expose the a-IGZO TFTs (Fig. 1a) to monochromatic light of variable wavelength (800 to $172 \mathrm{~nm})$. We show that photon energies less than $3.0 \mathrm{eV}$ induce small changes in the performance of the a-IGZO TFTs, whereas deep UV light $(7.2 \mathrm{eV})$ induces a large and rigid negative threshold-voltage shift $\left(\Delta \mathrm{V}_{\mathrm{TH}}>20 \mathrm{~V}\right)$, as well as a subthreshold hump and an increase in the subthreshold-voltage slope (SS). Through Time-of-Flight Secondary Ion Mass Spectrometry (ToF-SIMS) and X-ray photoelectron spectroscopy (XPS), we also show that $\mathrm{V}_{\mathrm{O}}$ states located at the top surface of the a-IGZO film are responsible for these changes. Radiated films contain a larger concentration of the $\mathrm{V}_{\mathrm{O}}$ states than pristine films, indicating photo creation of the $\mathrm{V}_{\mathrm{O}}$ states in addition to their photoionization.

Using TCAD (Technology Computer-Aided Design) simulation, we verify that the hump is a manifestation of the highly conductive backchannel and through the use of double gate TFTs with transparent top gates, we show that application of a back bias after light radiation suppresses the instability. Additionally, we show that the reduction of the a-IGZO film thickness in single gate TFTs can also suppress the light instability. These suppression methods are especially important for applications such as transparent displays where the use of light

${ }^{1}$ Department of Information Display, Kyung Hee University, Seoul 02447, South Korea. ${ }^{2}$ LG Electronics, Seoul 17709, South Korea. ${ }^{\circledR}$ email: mallory@khu.ac.kr 

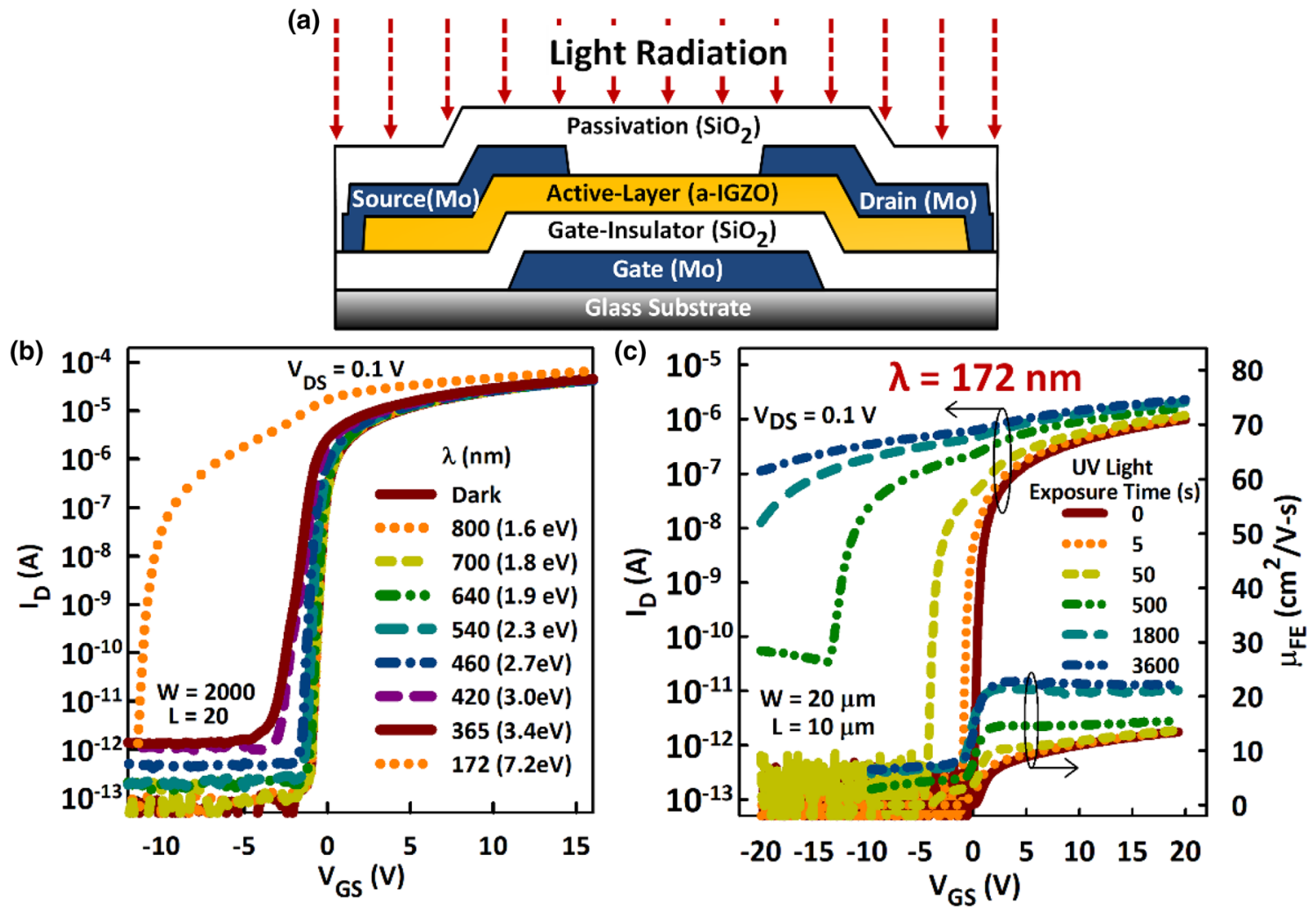

Figure 1. Effect of light radiation on the performance of a-IGZO TFTs. (a) Schematic cross-section of a-IGZO TFTs. (b) Transfer characteristics in dark and after radiation with monochromatic light of varying wavelength $(\lambda)$ for $500 \mathrm{~s}$. (c) Transfer characteristics and field-effect mobility $\left(\mu_{\mathrm{FE}}\right)$ as a function of exposure time to deep UV light $\left(\lambda=172 \mathrm{~nm}\right.$ and intensity of $\left.400 \mathrm{~mW} / \mathrm{cm}^{2}\right)$. Deep UV light radiation induces a large negative threshold voltage shift that is accompanied by a subthreshold hump and an increase in subthreshold voltage swing, as well as an increase in $\mu_{\mathrm{FE}}$.

shields is not permissible. These results support photo creation and ionization of $\mathrm{V}_{\mathrm{O}}$ as the main cause of light instability in a-IGZO TFTs and provide some insights on how to minimize the effect.

\section{Results and discussion}

Effect of light radiation. Figure $1 \mathrm{~b}$ shows the effects of monochromatic light on the performance of the a-IGZO TFTs. The wavelength of the light $(\lambda)$ is varied from 800 to $172 \mathrm{~nm}$, which corresponds to photon energy of 1.6 to 7.2 in electron volts $(\mathrm{eV})$, and the transfer characteristics are measured after light irradiation for $500 \mathrm{~s}$. Although small, the negative $\Delta \mathrm{V}_{\mathrm{TH}}$ after irradiation with photon energies less than $3.0 \mathrm{eV}$ suggests photoexcitation from sub-gap states ${ }^{22}$. A slight jump in the $\Delta \mathrm{V}_{\mathrm{TH}}$ is apparent for photon energies in the range of 3.0-3.4 eV and indicates the onset of band-to-band excitation. The photon energy of the deep UV light $(\sim 7.2 \mathrm{eV})$ is large enough to induce substantial negative $\Delta \mathrm{V}_{\mathrm{TH}}$ (Fig. 1b). For a clear understanding of the effects of light in the a-IGZO TFTs, we therefore use the deep UV light $(\lambda=172 \mathrm{~nm})$ in all investigations that follow. The negative $\Delta \mathrm{V}_{\mathrm{TH}}$ induced by deep UV light is accompanied by an increase in SS and the formation of a 'hump' in the transfer characteristics, which increases with exposure time (Fig. 1c). Also, quite noticeable is that the $\mu_{\mathrm{FE}}$ doubles after radiating the TFTs with deep UV for 3,600 s, consistent with a photo-induced increase in free carrier concentration.

Flat band parameters extracted from the combined analysis of the $\mathrm{I}_{\mathrm{D}}-\mathrm{V}_{\mathrm{GS}}$ (Fig. 2a) and C-V (Fig. 2b) characteristics are listed in Table 1. Detailed extraction methods can be found in Ref. 17. From the plot of surface potential $\left(\Psi_{\mathrm{S}}\right)$ vs. $\mathrm{V}_{\mathrm{GS}}$ (Fig. $\left.2 \mathrm{c}\right)$, the flat band voltage $\left(\mathrm{V}_{\mathrm{FB}}\right)$, taken as the $\mathrm{V}_{\mathrm{GS}}$ corresponding to $\Psi_{\mathrm{S}}=0 \mathrm{~V}$, decreases from 0.36 to $-5.89 \mathrm{~V}$ after light radiation. At the same time, the Fermi level $\left(\mathrm{E}_{\mathrm{F}}\right)$ moves closer to the conduction band $\left(\mathrm{E}_{\mathrm{C}}\right)$ by approximately $0.023 \mathrm{eV}$ and flat band carrier concentration $\left(\mathrm{n}_{\mathrm{FB}}\right)$ increases from $1.4 \times 10^{16}$ to $3.4 \times 10^{16} \mathrm{~cm}^{-3}$. Interface trap density $\left(\mathrm{N}_{\mathrm{int}}\right.$, the algebraic sum of negative and positive interface charge density) also increases from $-7.7 \times 10^{10}$ to $3.7 \times 10^{11} \mathrm{~cm}^{-2} \mathrm{eV}^{-1}$, while gap trap density per unit energy $\left(\mathrm{dN}_{\text {gap }} / \mathrm{dE}\right.$, the sum of interface and bulk density of states) increases from $1.3 \times 10^{12}$ to $3.6 \times 10^{12} \mathrm{~cm}^{-2} \mathrm{eV}^{-1}$. Note that a negative value of $\mathrm{N}_{\text {int }}$ indicates that negative charge exceed positive charge by that amount and vice-versa, given that $\mathrm{N}_{\text {int }}$ is the algebraic sum of positive and negative interface charge density.

These photoinduced changes in $\mu_{\mathrm{FE}}, \mathrm{SS}, \mathrm{n}_{\mathrm{FB}}, \mathrm{V}_{\mathrm{FB}}, \mathrm{E}_{\mathrm{F}}-\mathrm{E}_{\mathrm{C}}, \mathrm{N}_{\mathrm{it}}$, and $\mathrm{dN}_{\mathrm{gap}} / \mathrm{dE}$ are all consistent with accumulation/trapping of net positive charge at the gate-insulator/a-IGZO interface and creation of defects in the a-IGZO layer. The increase in SS indicates formation of the defects and given that $\mu_{\mathrm{FE}}$ increased and $\mathrm{E}_{\mathrm{F}}$ moved closer to $\mathrm{E}_{\mathrm{C}}$, some of these defects must be in the bulk of the a-IGZO and donor-like. The defects must also be positively 

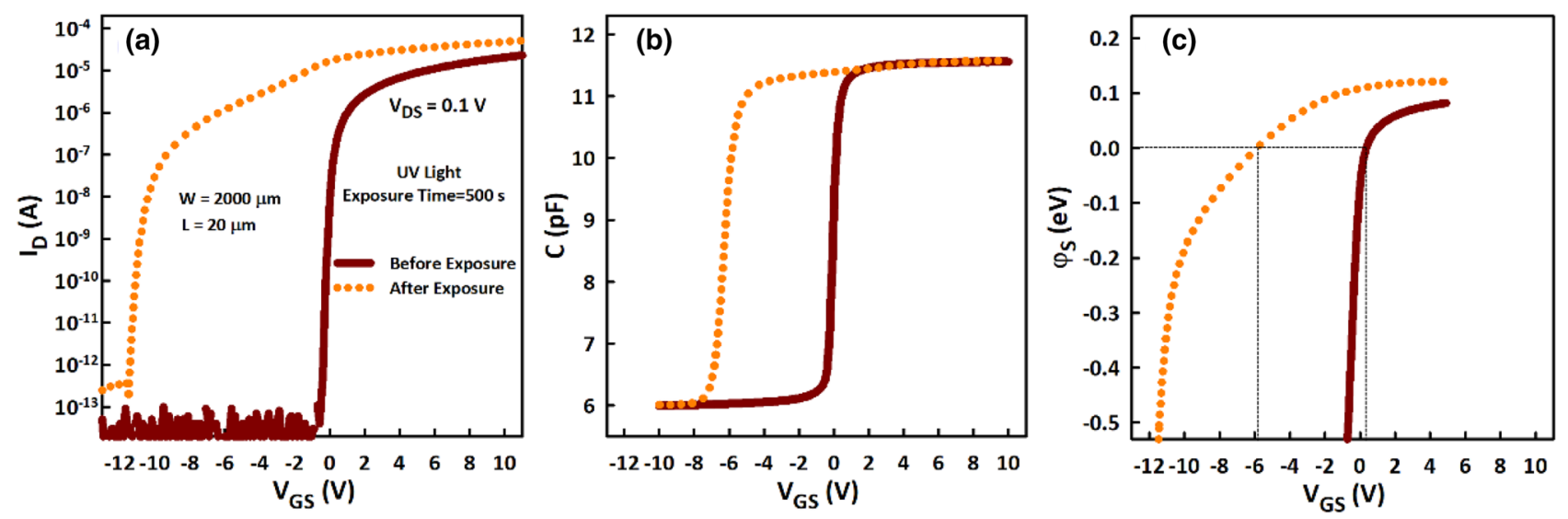

Figure 2. TFT characteristics used to determine the flat band parameters before and after deep UV light $(\lambda=172 \mathrm{~nm})$ radiation. (a) Transfer $\left(\mathrm{I}_{\mathrm{D}}{ }^{-} \mathrm{V}_{\mathrm{GS}}\right)$ characteristics. (b) Capacitance-voltage $\left(\mathrm{C}^{-} \mathrm{V}_{\mathrm{GS}}\right)$ characteristics. (c) Extracted surface potential $\left(\psi_{\mathrm{s}}\right)$ as a function of $\mathrm{V}_{\mathrm{GS}}$. The flat band voltage $\left(\mathrm{V}_{\mathrm{FB}}\right)$, which is taken as the $\mathrm{V}_{\mathrm{GS}}$ corresponding to $\psi_{\mathrm{S}}=0 \mathrm{eV}$, decreases from 0.36 to $-5.89 \mathrm{~V}$ after deep $\mathrm{UV}$ radiation.

\begin{tabular}{|l|l|c|c|l|l|}
\hline & $\mathbf{E}_{\mathrm{C}^{-}} \mathbf{E}_{\mathrm{F}}(\mathbf{e V})$ & $\mathbf{V}_{\mathrm{FB}}(\mathrm{V})$ & $\mathbf{N}_{\mathrm{it}} \mathbf{c m}^{-2} \mathbf{e V}^{-1}$ & $\mathbf{n}_{\mathrm{FB}}\left(\mathrm{cm}^{-3}\right)$ & $\mathbf{d N}_{\mathrm{gap}} / \mathbf{d E}_{\left(\mathbf{c m}^{-2} \mathbf{e V}^{-1}\right)}$ \\
\hline Pristine & 0.152 & 0.36 & $-7.7 \times 10^{10}$ & $1.4 \times 10^{16}$ & $1.3 \times 10^{12}$ \\
\hline After UV & 0.129 & -5.89 & $3.7 \times 10^{11}$ & $3.4 \times 10^{16}$ & $3.6 \times 10^{12}$ \\
\hline
\end{tabular}

Table 1. Flat and parameters.

charged (ionized), as the value of $\mathrm{N}_{\mathrm{it}}$ changed from a negative to a positive number, making the increase in $\mathrm{n}_{\mathrm{FB}}$ a sum of band-to-band and sub-gap photoexcitation.

Recovery after UV light radiation. The photoinduced negative $\Delta \mathrm{V}_{\mathrm{TH}}$ is quite repeatable over many samples with varying channel dimensions. In particular, the $\Delta \mathrm{V}_{\mathrm{TH}}$ is independent of $\mathrm{L}$ (Supplementary Fig. S1) and rigid such that recovery in the dark is almost negligible at temperatures $\leq 100{ }^{\circ} \mathrm{C}$ (Fig. 3). At $150{ }^{\circ} \mathrm{C}$, the transfer characteristics recover slowly and fail to return to the initial state even if the TFTs stay in the dark for a few days (Fig. 3c). Complete recovery is only achievable after annealing at $250{ }^{\circ} \mathrm{C}$ in vacuum for two or more hours. Therefore, the ionized donor-like defects generated by light radiation must be metastable states ${ }^{23,24}$. However, the exceedingly small but rapid initial recovery (within $100 \mathrm{~s}$ ) at low temperature could be due to delayed electron-hole recombination via non-metastable gap states.

As shown in the Fig. $3 \mathrm{~d}$, the time dependent $\Delta \mathrm{V}_{\mathrm{TH}}$ during the recovery period is well described by the stretched exponential equation given by

$$
\left|\Delta V_{T H}(t)\right|=V_{O}\left\{1-\exp \left[-\left(\frac{t}{\tau}\right)^{\beta}\right]\right\}
$$

where $\mathrm{V}_{0}$ is the $\Delta \mathrm{V}_{\mathrm{TH}}$ at infinite time. The equation describes the superposition of processes with a spread of time constants (quantified by the stretch parameter $\beta<1$ ) around an average value $\tau$. A plot of the time constant $\tau$ as a function of temperature can be fitted to a straight line (Fig. 3e) described by the equation

$$
\tau=\tau_{0} \exp \left(E_{\tau} / k_{B} T\right)
$$

where $\mathrm{T}$ is the temperature in kelvins and $\mathrm{k}_{\mathrm{B}}$ is the Boltzmann constant. This equation is typical of thermally activated processes with an activation energy $\mathrm{E}_{\tau}$. Here, the $\mathrm{E}_{\tau}$ required to reverse the formation of the defects created during the deep UV light radiation is estimated to be approximately $0.99 \mathrm{eV}$. This value is close to the activation energy previously obtained for the creation of a $\mathrm{V}_{\mathrm{O}}$ related double donors during NBIS ${ }^{25}$.

Location of defects. The nature of these defects is investigated by XPS depth profile analysis of thin-film stacks (glass $/ \mathrm{SiO}_{2} / \mathrm{a}-\mathrm{IGZO} / \mathrm{SiO}_{2}$ ) before and after UV exposure (Fig. 4). The $\mathrm{O} 1 \mathrm{~s}$ spectrum is deconvoluted into four energy peaks: $\mathrm{O}-\mathrm{M}, \mathrm{V}_{\mathrm{O}}, \mathrm{O}-\mathrm{H}$, and $\mathrm{Si}-\mathrm{O}$. Peak $\mathrm{O}-\mathrm{M}$, which is centered at $529.9 \mathrm{eV}$, is attributed to $\mathrm{O}^{2-}$ ions binding with In, $\mathrm{Ga}$, and $\mathrm{Zn}$ atoms-and thus represents the quantity of the oxygen atoms in a fully oxidized stoichiometric environment. Peak O-H is related to metal-OH (hydroxyl) bonds and centered at 532.1, whereas peak $\mathrm{Si}-\mathrm{O}$ is related to $\mathrm{Si}-\mathrm{O}$ bonds and centered at 532.4 . The $\mathrm{V}_{\mathrm{O}}$ peak at $531.2 \mathrm{eV}$ stems from the deficiently bonded oxygen in the a-IGZO layer containing nonstoichiometric oxide species, such as $\operatorname{In}_{2} \mathrm{O}_{3-\mathrm{x}}, \mathrm{Ga}_{2} \mathrm{O}_{3-\mathrm{x}}$, and $\mathrm{ZnO}_{1-\mathrm{x}}$, which are associated with $\mathrm{V}_{\mathrm{O}}{ }^{26,27}$. Area percentages of each peak before and after radiation are listed in Table 2 . 

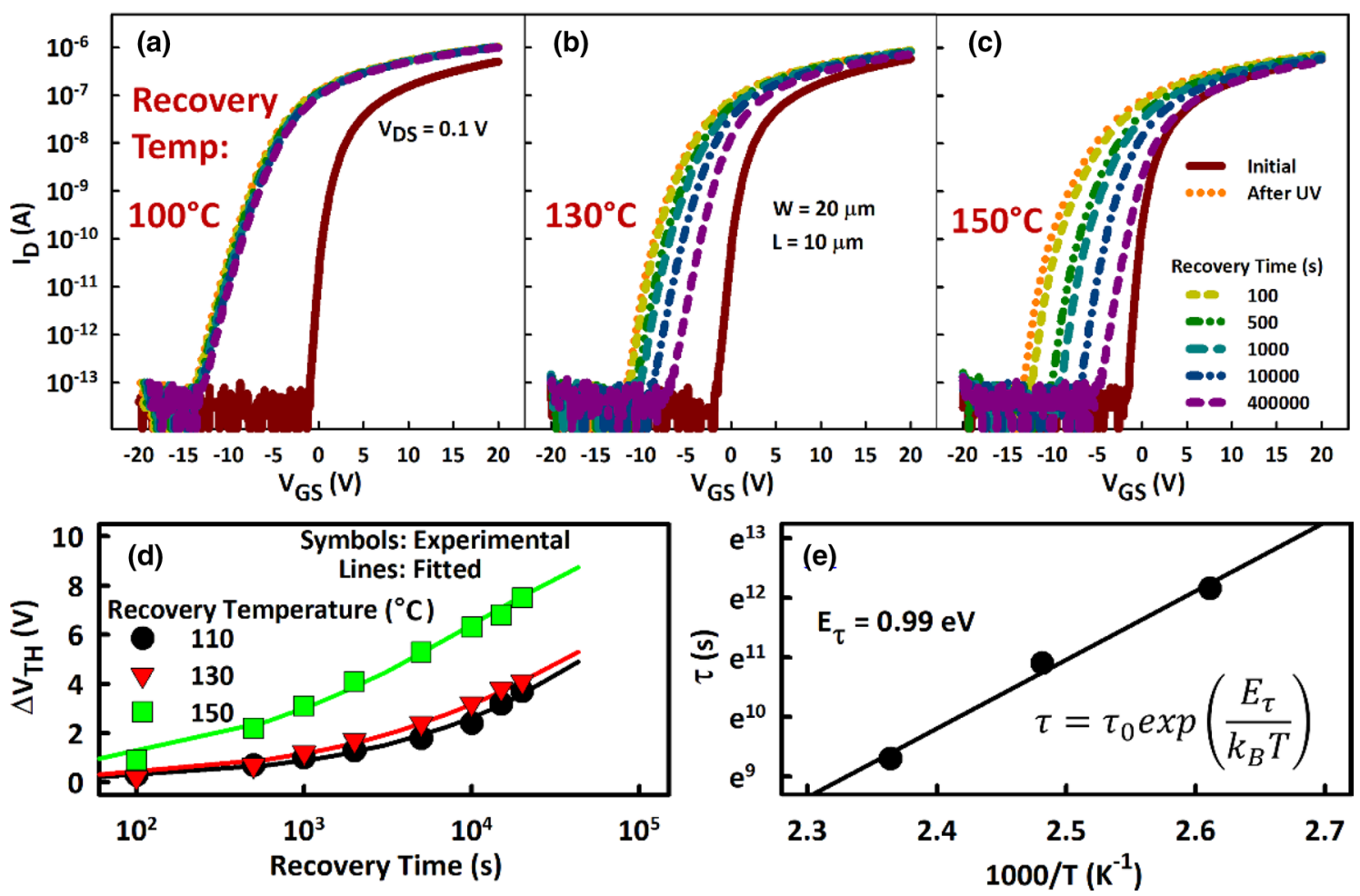

Figure 3. Recovery of transfer characteristics of a-IGZO TFTs at (a) $100^{\circ} \mathrm{C}$, (b) $130{ }^{\circ} \mathrm{C}$, and (c) $150{ }^{\circ} \mathrm{C}$ after deep UV light $\left(\lambda=172 \mathrm{~nm}\right.$ ) radiation for $500 \mathrm{~s}$. Recovery only occurs at temperature $>100^{\circ} \mathrm{C}$. (d) Threshold voltage shift $\left(\Delta \mathrm{V}_{\mathrm{TH}}\right)$ as a function of recovery time from the deep UV light radiation stress. (e) Plot of the average time constant $(\tau)$ as an inverse function of temperature (Arrhenius plot). The activation energy for the recovery process $\left(\mathrm{E}_{\tau}=0.99 \mathrm{eV}\right)$ is obtained from the slope of the straight line.

While the number of $\mathrm{Si}-\mathrm{O}$ and $\mathrm{OH}$-related defects is negligible in the bulk (Fig. 4b), a significant amount is present at the top (Fig. 4a) and bottom (Fig. 4c) surfaces of the pristine a-IGZO film as expected. The amount of $\mathrm{V}_{\mathrm{O}}$ is also larger at the surfaces compared to the bulk. Similar situations have been reported before, identifying $\mathrm{V}_{\mathrm{O}}$ as a surface feature, confined within $0.5 \mathrm{~nm}$ of the top surface of the film ${ }^{16,28}$. While deep UV radiation results in the creation of very few $\mathrm{V}_{\mathrm{O}}$ defects in the bulk (Fig. 4e) and at the bottom surface (Fig. 4f) of the a-IGZO, a substantial amount is created at the top surface (Fig. 4d), where the area percentage increases from 10 to $24 \%$ (Table 2). The area percentage of the Si-O peak also increases from 15 to $28 \%$ at the top surface, indicating the diffusion of $\mathrm{Si}$ atoms into the a-IGZO layer, possibly from the broken weak $\mathrm{Si}-\mathrm{O}$ bonds at the top interface. It should be pointed out that a large overlap exists between the energy peaks $\mathrm{O}-\mathrm{H}(532.1 \mathrm{eV})$ and $\mathrm{Si}-\mathrm{O}(532.4 \mathrm{eV})$, making it difficult to separate the two. To ensure a reasonable peak ratio, we fixed the full width half-maximum of all components to 1 .

The use of optical electron paramagnetic resonance (EPR) experiments has shed light on the nature of $\mathrm{V}_{\mathrm{O}}$ in $\mathrm{ZnO}$ single crystals ${ }^{29,30} . \mathrm{V}_{\mathrm{O}}$ bind two electrons in their electrically neutral state $\left(\mathrm{V}_{\mathrm{O}}{ }^{0}\right)$ but can also exist in a singly ionized $\left(\mathrm{V}_{\mathrm{O}}{ }^{+}\right)$and doubly ionized $\left(\mathrm{V}_{\mathrm{O}}{ }^{2+}\right)$ state. The increase in the concentration of $\mathrm{V}_{\mathrm{O}}$ states at the top surface of the a-IGZO film after light radiation indicates photo-creation of the $\mathrm{V}_{\mathrm{O}}$. However, this increase is too small to account for $\Delta \mathrm{V}_{\mathrm{TH}}>10 \mathrm{~V}$ after light radiation (Fig. 1c). A plausible explanation would be the photoionization of existing and newly created $\mathrm{V}_{\mathrm{O}}{ }^{0}$ to $\mathrm{V}_{\mathrm{O}}{ }^{2+}$ states-a process which donates two electrons to $\mathrm{E}_{\mathrm{C}}$.

The presence of two electrons in $\mathrm{V}_{\mathrm{O}}{ }^{0}$ triggers the surrounding $\mathrm{Zn}^{2+}$ ions to move inwardly, reducing the physical size of the vacancy. Consequently, the binding energy increases as the overlapping between the $\mathrm{Zn}^{2+}$ wave functions intensifies, such that $\varepsilon(+/ 0)<\varepsilon(2+/ 0)<\varepsilon(2+/+)$, where $\varepsilon(+/ 0)$ is the transition energy from the $\mathrm{V}_{\mathrm{O}}{ }^{+}$to $\mathrm{V}_{\mathrm{O}}$ and similarly for the other two cases ${ }^{31-33}$. $\mathrm{V}_{\mathrm{O}}$ are thus said to have a negative correlation energy $\mathrm{U}$ and the $\mathrm{V}_{\mathrm{O}}{ }^{+}$is unstable due to the presence of either $\mathrm{V}_{\mathrm{O}}{ }^{2+}$ or $\mathrm{V}_{\mathrm{O}}{ }^{0}$ with a lower formation energy but can be observed under nonequilibrium conditions such as under illumination ${ }^{34-36}$. This means that only the presence of $\mathrm{V}_{\mathrm{O}}{ }^{0}$ or $\mathrm{V}_{\mathrm{O}}{ }^{2+}$ is expected at thermal equilibrium.

The transition from $\mathrm{V}_{\mathrm{O}}$ to $\mathrm{V}_{\mathrm{O}}{ }^{2+}$ is thus accompanied by lattice relaxation that raises the energy level of $\mathrm{V}_{\mathrm{O}}{ }^{2+}$ after photoionization and leads to metastability of the $\mathrm{V}_{\mathrm{O}}{ }^{2+}$ states. In fact, this lattice relaxation can make energy levels of the $\mathrm{V}_{\mathrm{O}}{ }^{2+}$ states degenerate with $\mathrm{E}_{\mathrm{C}}{ }^{31,32}$. If that occurs, free electrons occupying lower lying states in the conduction band minimum will need to be activated, thermally or otherwise, to these higher $\mathrm{V}_{\mathrm{O}}{ }^{2+}$ state levels for the reverse reaction, making the $\mathrm{V}_{\mathrm{O}}{ }^{2+}$ a metastable donor defect. Being ionized states that are degenerate with the $\mathrm{E}_{\mathrm{C}}$, the $\mathrm{V}_{\mathrm{O}}{ }^{2+}$ will not be detected by XPS ${ }^{28}$. However, the negative $\Delta \mathrm{V}_{\mathrm{TH}}$ increase in SS after light radiation is consistent with the photo-creation of shallow states. Moreover, the binding energies of the In $3 \mathrm{~d}_{5 / 2}, \mathrm{Ga} 2 \mathrm{p}_{3 / 2}$, and 
Top Interface Bulk Bottom Interface

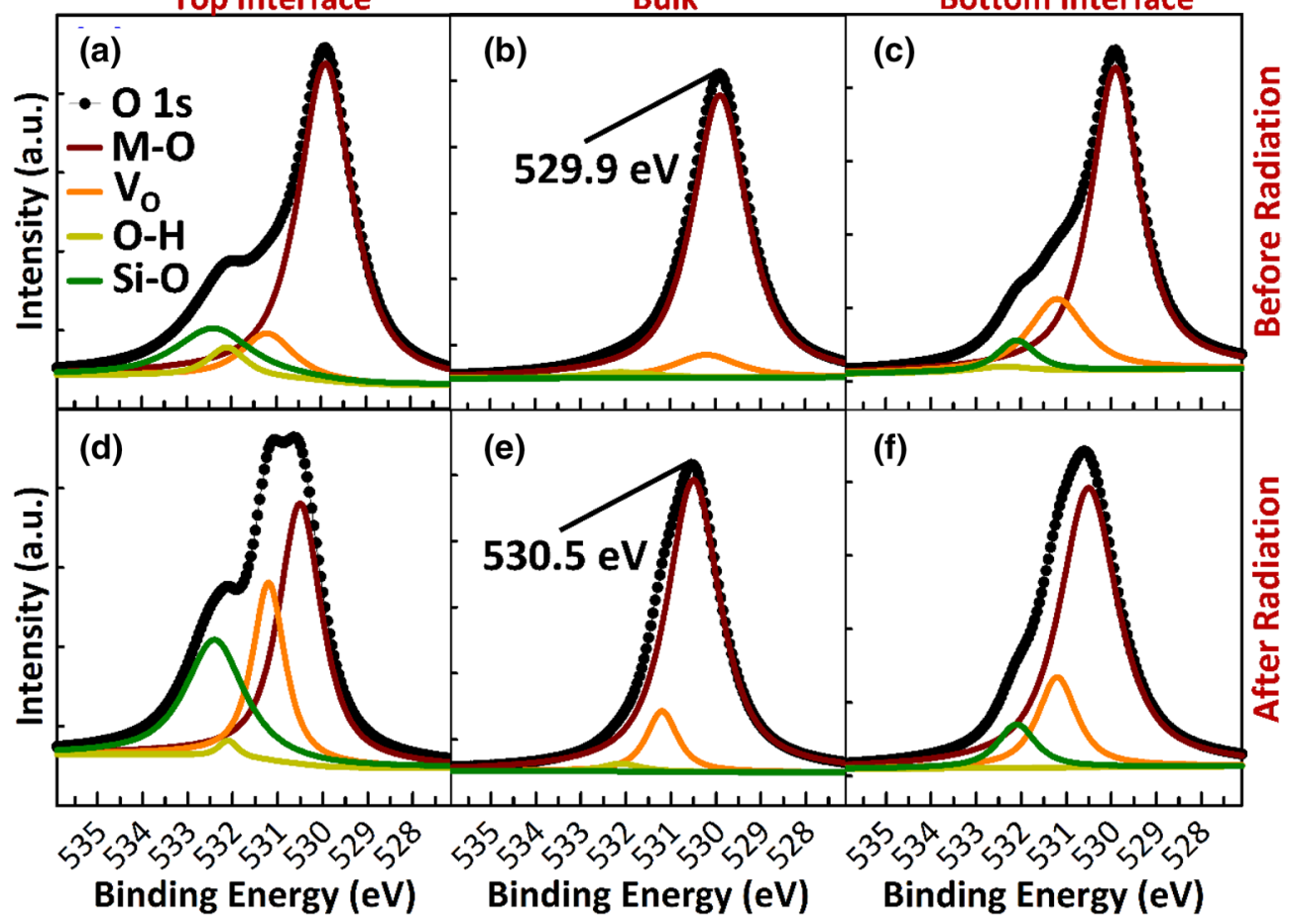

Figure 4. XPS results showing $\mathrm{O} 1 \mathrm{~s}$ spectra of thin-film stacks (glass $/ \mathrm{SiO}_{2} / \mathrm{a}-\mathrm{IGZO} / \mathrm{SiO}_{2}$ ) before (a-c) and after (d-f) deep UV light exposure at the top surface (a and d), in the bulk (b and $\mathbf{e}$ ), and at the bottom surface (c and f) of the a-IGZO film. The $\mathrm{O} 1 \mathrm{~s}$ spectrum is deconvoluted into four energy peaks: $\mathrm{M}-\mathrm{O}, \mathrm{V}_{\mathrm{O}}, \mathrm{O}-\mathrm{H}$, and $\mathrm{Si}-\mathrm{O}$. Peak $\mathrm{O}-\mathrm{M}$, which is centered at $529.9 \mathrm{eV}$, is attributed to $\mathrm{O}^{2-}$ ions binding with $\mathrm{In}, \mathrm{Ga}$, and $\mathrm{Zn}$ atoms-and thus represents the quantity of the oxygen atoms in a fully oxidized stoichiometric environment. The $V_{O}$ peak at $531.2 \mathrm{eV}$ stems from the deficiently bonded oxygen in the a-IGZO layer containing nonstoichiometric oxide species, such as $\mathrm{In}_{2} \mathrm{O}_{3-\mathrm{x}}, \mathrm{Ga}_{2} \mathrm{O}_{3-\mathrm{x}}$, and $\mathrm{ZnO}_{1-\mathrm{x}}$, which are associated with $\mathrm{V}_{\mathrm{O}}$. Peak $\mathrm{O}-\mathrm{H}$ is related to metal-OH (hydroxyl) bonds and centered at $532.1 \mathrm{eV}$, while Peak Si-O is related to Si-O bonds and centered at $532.4 \mathrm{eV}$.

\begin{tabular}{|l|l|l|l|l|l|l|l|l|}
\hline & \multicolumn{3}{|l}{ M-O (\%) } & \multicolumn{2}{l|}{ V } & O-H (\%) & \multicolumn{2}{l|}{ Si-O (\%) } \\
\cline { 2 - 10 } & Before UV & After UV & Before UV & After UV & Before UV & After UV & Before UV & After UV \\
\hline Top interface & 70 & 46 & 10 & 24 & 5 & 2 & 15 & 28 \\
\hline Bulk & 91 & 88 & 7 & 11 & 2 & 1 & 0 & 0 \\
\hline Bottom interface & 73 & 70 & 20 & 21 & 1 & 0 & 6 & 8 \\
\hline
\end{tabular}

Table 2. Area percentages of metal-oxygen $(\mathrm{M}-\mathrm{O})$, oxygen vacancy $\left(\mathrm{V}_{\mathrm{O}}\right)$, hydroxyl $(\mathrm{O}-\mathrm{H})$, and siliconoxygen $(\mathrm{Si}-\mathrm{O})$ peaks from deconvoluted $\mathrm{O} 1 \mathrm{~s}$ spectra.

$\mathrm{Zn} 2 \mathrm{p}_{3 / 2}$ peaks all show a shifting towards higher binding energy, indicating a decrease in the electron density around the metals (Supplementary Fig. S2). This is consistent with ionization.

Hydrogen also plays a role in the instability of the a-IGZO TFTs. In fact, a high concentration of hydrogen (in the order of $10^{20} \mathrm{~cm}^{-3}$ ) has been observed in a-IGZO thin films, without intentional exposure of the films to hydrogen during their deposition ${ }^{37,38}$. Incorporated hydrogen can fill $\mathrm{V}_{\mathrm{O}}$ sites in a-IGZO films, forming stable +1 charge states as donors ${ }^{39}$. If these states are also degenerate with the $\mathrm{E}_{\mathrm{C}}$, they will be hard to detect by XPS. However, a significant increase in the amount of hydrogen after UV light radiation is detected by ToF-SIMS depth profiling of the $\mathrm{SiO}_{2} / \mathrm{IGZO} / \mathrm{SiO}_{2}$ structures used in this study. The increase is mainly confined to the top surface of the a-IGZO layer as can be seen in Supplementary Fig. S3d. Additionally, ToF-SIMS also detected a smaller amount of gallium, zinc, and oxygen at the top interface compared to the bulk (Supplementary Fig. S3), which is consistent with a larger population of defects at the top interface.

Hydrogen impurities generate two types of defects, depending on whether they are bonded to an oxygen $(\mathrm{OH})$ or to a metal $(\mathrm{M}-\mathrm{H})$ site. The $\mathrm{OH}$ defects have negative formation energy, implying a spontaneous formation whenever hydrogen is present. These defects do not generate states in the gap but act as donors until a high electron concentration is achieved, after which hydrogen starts to bind itself to metal sites, forming acceptors which compensate for the surplus of electrons in the a-IGZO. As the $\mathrm{M}-\mathrm{H}$ bond requires an electron to form, it thus helps to limit the carrier concentration in a-IGZO, and forms states just above the $\mathrm{E}_{\mathrm{V}}{ }^{40}$. ToF-SIMS results 


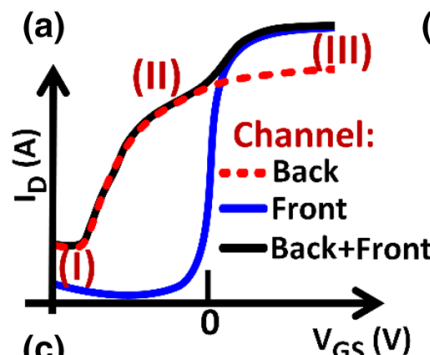

(c)

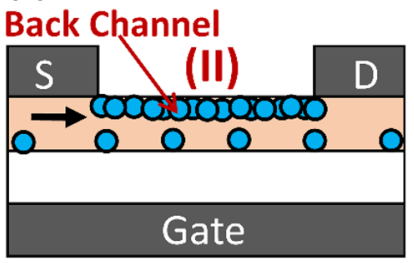

(b)

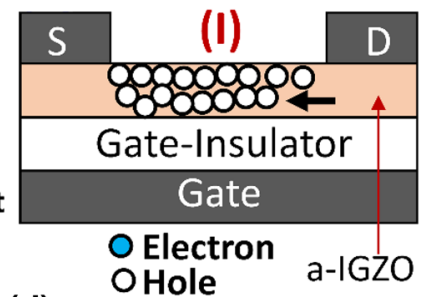

(d)

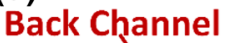

Figure 5. Mechanism for "hump" formation in the transfer characteristics after deep UV light $(\lambda=172 \mathrm{~nm})$ radiation. (a) Schematic transfer characteristics showing the contributions of the back and front channel currents to the total current (Back+Front). (b) Off-state current increases due to the flow of holes from the drain (D) to the source (S) when $\mathrm{V}_{\mathrm{GS}}$ is negative (region I). (c) Only the backchannel is conducting when $\mathrm{V}_{\mathrm{GS}}$ is close to zero volts (region II). (d) Both the back and front channels are conducting when $\mathrm{V}_{\mathrm{GS}}$ is positive (region III).

suggest the bonding of hydrogen and indium, given that both significantly increased at the top interface after UV light radiation (Supplementary Fig. S3).

Origin of the subthreshold hump. The XPS analysis has reviewed that the top surface of the a-IGZO layer is the most affected by light radiation, showing a sizeable increase in the number of $\mathrm{V}_{\mathrm{O}}$ and $\mathrm{Si}-\mathrm{O}$ defects. Additionally, calculations for $\operatorname{In}_{2} \mathrm{O}_{3}$ crystals have shown that $\mathrm{V}_{\mathrm{O}}$ can behave as shallow donors when located at the surface rather than in the bulk ${ }^{41}$. Furthermore, the positive shift in binding energy of the In $3 \mathrm{~d}_{5 / 2}, \mathrm{Ga} 2 \mathrm{p}_{3 / 2}$, and $\mathrm{Zn} 2 \mathrm{p}_{3 / 2}$ peaks is mainly confined to the top half of the a-IGZO film (Supplementary Fig. S2) and a linear plot of the transfer characteristics in Fig. 1c shows two different slopes for negative and positive $\mathrm{V}_{\mathrm{GS}}$ (Supplementary Fig. S4), which clearly indicates the presence of two logical channels with two different resistances. Taking all this into consideration, the formation of the subthreshold hump in the transfer characteristics after deep UV radiation can thus be explained by the creation of shallow donors at the top surface of the a-IGZO film. This will create a parasitic channel (backchannel) with a conductance that is higher than that of the a-IGZO bulk (frontchannel) $)^{42}$.

Figure 5 shows how this conductive backchannel is manifested as a hump in the transfer characteristics of the a-IGZO TFTs post radiation. In Fig. 5a, the transfer characteristics are divided into three regions, labeled I, II, and III. In region I, the a-IGZO layer is depleted of electrons due to the strong negative $\mathrm{V}_{\mathrm{GS}}$ and only holes remain in the channel. In a-IGZO, it is difficult to induce holes with negative $V_{G S}$, owing to the large concentration of $V_{O}$ located less than $1 \mathrm{eV}$ above $\mathrm{E}_{\mathrm{V}}{ }^{43}$. So, these holes must be the photogenerated holes that have not yet recombined. The holes drift towards the source $(S)$ under the influence of the positive $V_{\text {DS }}$, resulting in a small hole current and lowering of the source barrier for electron injection (Fig. 5b) ${ }^{23}$, 44 . In region II, electron accumulation begins at the top surface of the a-IGZO, and the backchannel becomes conducting, while the frontchannel is still not (Fig. 5c). In region III, both the front and backchannel are conducting, and $I_{D}$ is the sum of the currents flowing in the two channels (Fig. 5d).

In region III, the current due to the backchannel is lower than that of the bulk (front) (Fig. 5a) because the latter is thicker than the former. TCAD simulation of the TFT transfer characteristics with (Fig. 6a) and without (Fig. 6b) a highly conductive top surface of the a-IGZO film, also yielded the same results (Fig. 6c), verifying the hump formation mechanism. Here, a $2 \mathrm{~nm}$-thick a-IGZO layer with a donor concentration $\left(\mathrm{n}_{\mathrm{gd}}\right)$ of $7 \times 10^{18} \mathrm{~cm}^{-3}$ is used to represent the highly conductive a-IGZO top surface (Fig. 6b). $\mathrm{n}_{\mathrm{gd}}$ of the bulk is $1 \times 10^{17} \mathrm{~cm}^{-3}$. Other density of states parameters have the same values as those reported $\mathrm{in}^{45}$. A depth profile analysis of the electron concentration (Fig. 6d) indicates that a highly conductive backchannel is responsible for the negative $\Delta \mathrm{V}_{\mathrm{TH}}$. Consistent with the mechanism for the "hump", only the backchannel is conductive when the $\mathrm{V}_{\mathrm{GS}}$ is negative (e.g., $\mathrm{V}_{\mathrm{GS}}=-10 \mathrm{~V}$ ) as shown in Fig. 6e. When the $\mathrm{V}_{\mathrm{GS}}$ is positive (e.g., $\mathrm{V}_{\mathrm{GS}}=10 \mathrm{~V}$ ), conduction occurs in both the backchannel and frontchannel (Fig. 6f).

It is important to note that the hump starts at the same point (at approximately $\mathrm{V}_{\mathrm{GS}}=0 \mathrm{~V}$ ), regardless of the UV light exposure time, although it progressively stretches into the negative $\mathrm{V}_{\mathrm{GS}}$ direction with increasing exposure time (Supplementary Fig. S4). This is consistent with the increase in the number of photoionized $\mathrm{V}_{\mathrm{O}}$ at the top surface of the a-IGZO film and the consequent increase in the backchannel current with UV exposure time. In other words, the negative $\Delta \mathrm{V}_{\mathrm{TH}}$ is mostly due to defects generated at the top surface of the a-IGZO film. Application of negative $\mathrm{V}_{\mathrm{GS}}$ during light illumination pushes the $\mathrm{E}_{\mathrm{F}}$ towards $\mathrm{E}_{\mathrm{V}}$ and increases the concentration of holes, favoring the formation of these defects, which is why the effect is larger under NBIS. 
(a) Without Conductive Backchannel

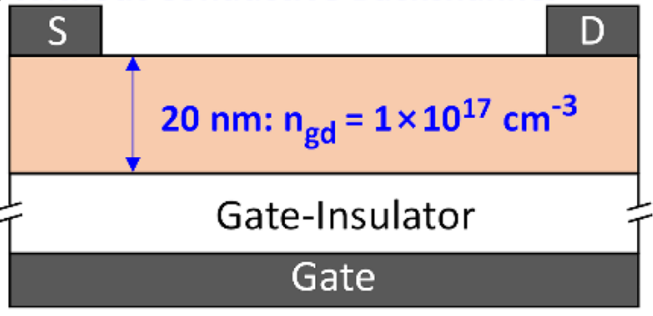

(c) -4

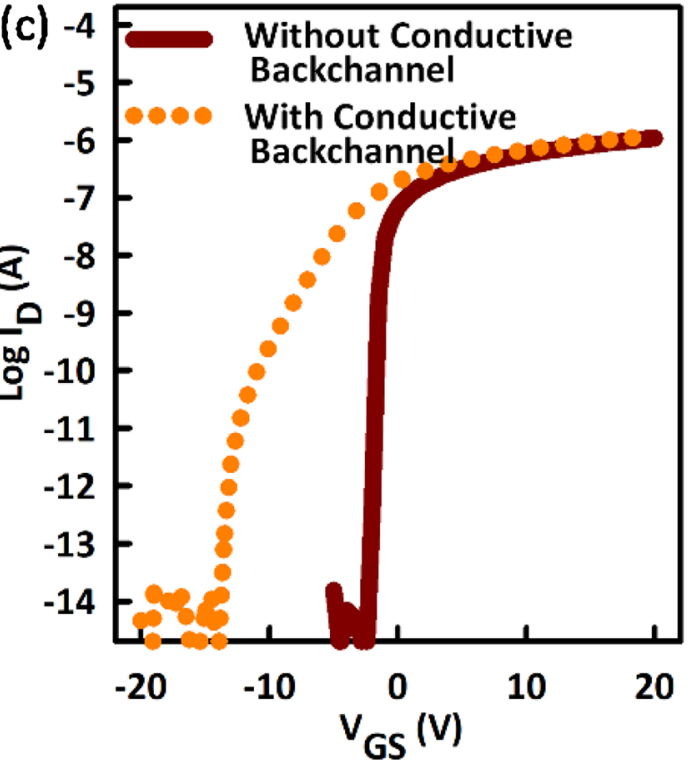

(e) $V_{G S}=-10 \mathrm{~V}$

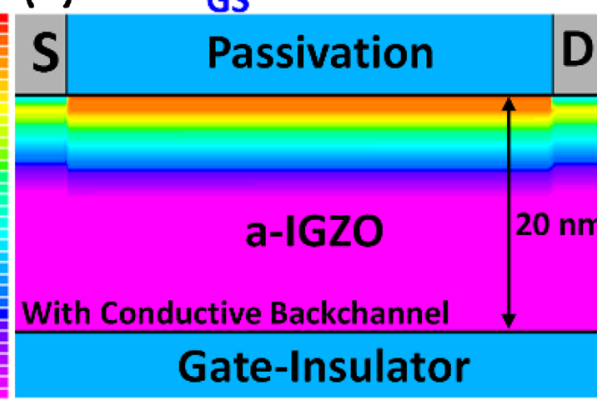

(b) With Conductive Backchannel
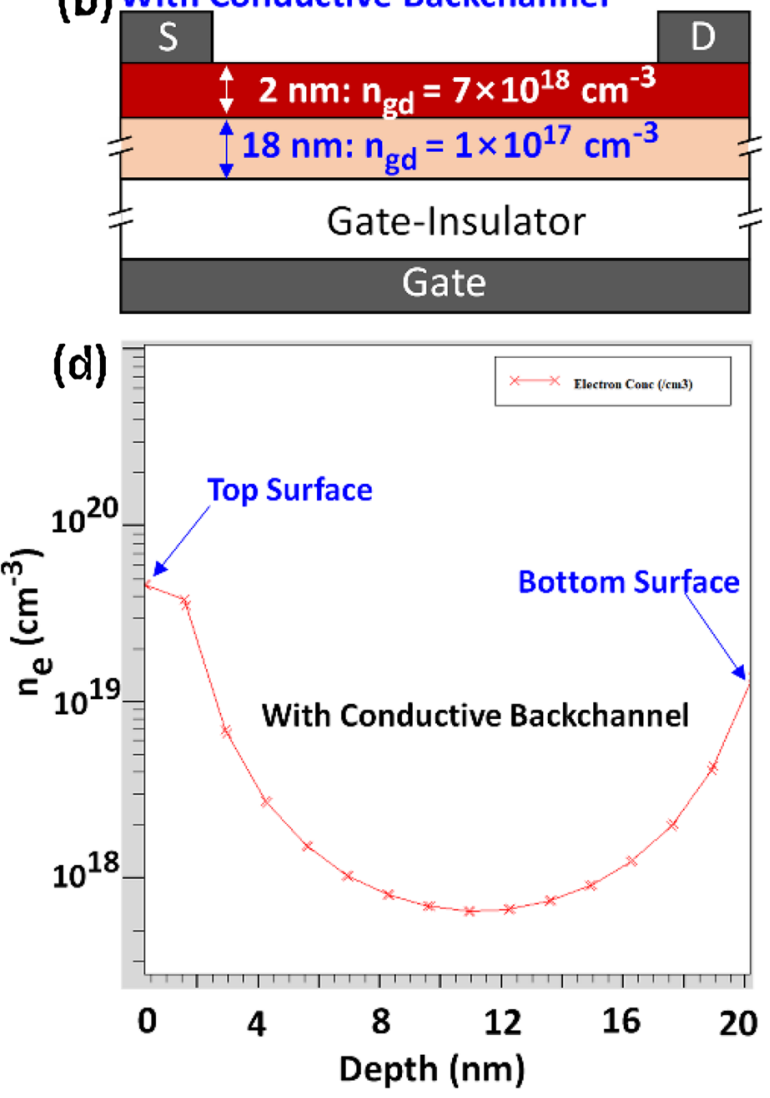

(f) $\quad \mathrm{V}_{\mathrm{GS}}=10 \mathrm{~V}$

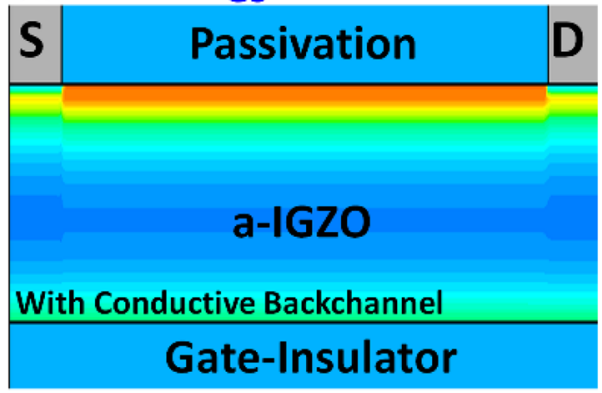

Figure 6. TCAD simulation of the effect of deep UV light radiation on a-IGZO TFTs. (a and $\mathbf{b})$ Schematics representing the TFT models used to simulate TFT characteristics (a) before and (b) after deep UV light radiation. A $2 \mathrm{~nm}$ thick a-IGZO film with a donor concentration $\left(\mathrm{n}_{\mathrm{gd}}\right)$ of $7 \times 10^{18} \mathrm{~cm}^{-3}$ is used to simulate the photoionization of neutral oxygen vacancies at the top surface of the a-IGZO film. $n_{\text {gd }}$ for the bulk is $1 \times 10^{17} \mathrm{~cm}^{-3}$. (c) Simulated transfer characteristics. (d) Line profile of the electron concentration $\left(\mathrm{n}_{\mathrm{e}}\right)$ from the top to the bottom surface when $\mathrm{V}_{\mathrm{GS}}=10 \mathrm{~V}$. (e and $\mathbf{f}$ ) Images showing the distribution of $\mathrm{n}_{\mathrm{e}}$ in the a-IGZO with a conductive backchannel when $(\mathbf{e}) \mathrm{V}_{\mathrm{GS}}=-10 \mathrm{~V}$ and $(\mathbf{f}) \mathrm{V}_{\mathrm{GS}}=10 \mathrm{~V}$. The presence of a conductive top surface induces a negative $\Delta \mathrm{V}_{\mathrm{TH}}$ and the "hump".

It is expected for one to suspect that the results presented herein show defect generation only at the top surface because absorption of light with high photon energy $(\sim 7.2 \mathrm{eV})$ is limited to the top surface. However, the penetration depth for $\lambda=172$ in a-IGZO has been reported to be $30 \mathrm{~nm}$ for intensity 8 times smaller than the one used herein ${ }^{46}$. In fact, by considering the a-IGZO film thickness (d) of $20 \mathrm{~nm}$ and incident light intensity $\left(\mathrm{I}_{0}\right)$ of $400 \mathrm{~mW} / \mathrm{cm}^{2}$, the transmitted light intensity $\left(\mathrm{I}_{\mathrm{t}}\right)$ can be estimated from

$$
I_{t}=I_{0} e^{-\alpha d}
$$

to be approximately $\sim 54 \mathrm{~mW} / \mathrm{cm}^{2}$, which is too high to eliminate absorption at the bottom surface of the a-IGZO. Here, $\alpha$ is the absorption coefficient, which is assumed to be approximately $10^{6} \mathrm{~cm}^{-1}$ for $\lambda=172 \mathrm{~nm}$ based on the extrapolation of previously published results ${ }^{47}$. Therefore, the origin of the light instability in a-IGZO TFTs is indeed due to the ionization of $\mathrm{V}_{\mathrm{O}}$ states that are intrinsic to the top surface of the a-IGZO films. 


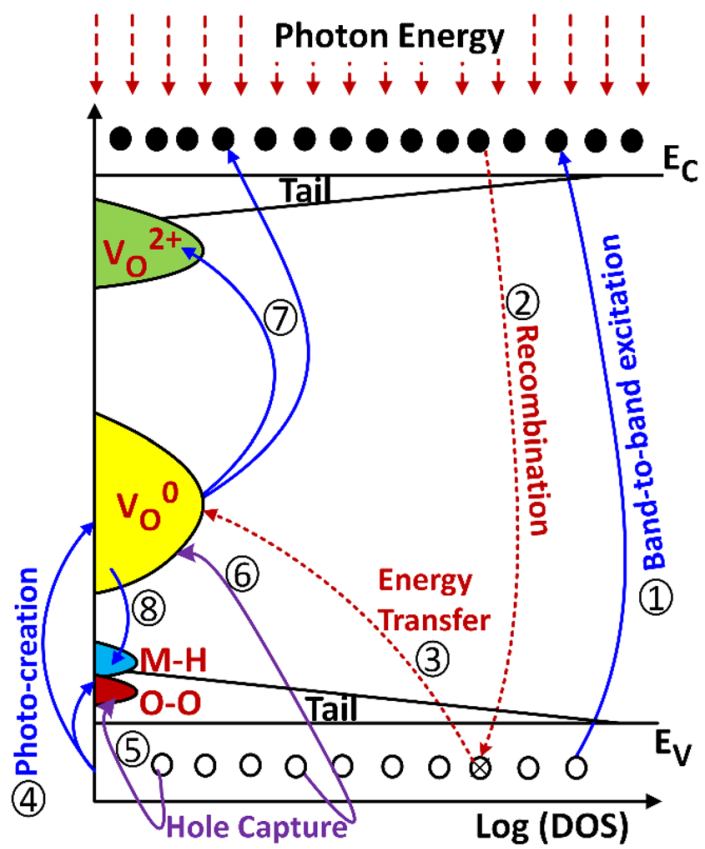

Figure 7. Defect creation under deep UV light illumination. (1) Band-to-band excitation. (2) Electron-hole $(\mathrm{e}-\mathrm{h})$ recombination. (3) Breaking of weak bonds to form neutral oxygen vacancies $\left(\mathrm{V}_{\mathrm{O}}{ }^{0}\right)$ using energy released from $\mathrm{e}-\mathrm{h}$ recombination and from the heat lost during the descent of electrons from higher to lower states in the conduction band $\left(\mathrm{E}_{\mathrm{C}}\right)$. (4) Photo-creation of $\mathrm{V}_{\mathrm{O}}{ }^{0}$ due to the high energy photons. (5) Formation of peroxides $(\mathrm{O}-\mathrm{O})$ via hole capture or bonding of two interstitial oxygen atoms. (6) Ionization of $\mathrm{V}_{\mathrm{O}}{ }^{0}$ to $\mathrm{V}_{\mathrm{O}}{ }^{2+}$ via hole capture. (7) Photoionization of $\mathrm{V}_{\mathrm{O}}^{0}$ to $\mathrm{V}_{\mathrm{O}}^{2+}$. Structural relaxation raises the energy level of $\mathrm{V}_{\mathrm{O}}{ }^{2+}$ relative to $\mathrm{V}_{\mathrm{O}}{ }^{0}$. (8) Formation of metal-hydrogen bonds $(\mathrm{M}-\mathrm{H})$ via electron capture. This event controls the maximum electron concentration. The numbers do not represent the order in which these events occur.

Defect creation mechanism. Thermodynamic calculations have estimated the formation energy of the $\mathrm{V}_{\mathrm{O}}{ }^{0}$ in a-IGZO to be approximately $4 \mathrm{eV}^{48}$, which is too high for the $\mathrm{V}_{\mathrm{O}}$ to be present in large amounts in native films, consistent with the bulk of the a-IGZO films presented herein (Fig. 4c). However, $4 \mathrm{eV}$ is less than the photon energy of the deep UV light $(\sim 7.2 \mathrm{eV})$, making their photo-creation possible. Furthermore, $\mathrm{V}_{\mathrm{O}}$ can be created from centers with weak or broken bonds in the presence of light, due to the release of energy from electron-hole recombination. Similarly, $\varepsilon(0 / 2+)$ can be greatly reduced through recombination of the electrons bound to the $\mathrm{V}_{\mathrm{O}}{ }^{0}$ with photogenerated holes, resulting in $\mathrm{V}_{\mathrm{O}}{ }^{2+}$.

The above-mentioned mechanism is similar to the Staebler Wronski effect in a-Si: $\mathrm{H}^{49}$, where hydrogen plays a major role in a mechanism known as bond switching ${ }^{50}$. In this case, a weak Si-Si bond is also broken by using the energy released from the recombination of photo-generated electron-hole pairs, and two stable dangling bonds can be formed if a hydrogen atom from a neighboring $\mathrm{Si}-\mathrm{H}$ bond is exchanged for one of the created dangling bonds. Therefore, atomic exchange after photo-creation of defects in a-IGZO with weak bonds present in the random lattice could play a role in the photo-creation of defects also in a-IGZO. Note that metal vacancies or interstitials are also present in the amorphous network of the $\mathrm{IGZO}^{35}$. Additionally, as hydrogen in the excess of $\sim 10^{20} \mathrm{~cm}^{-3}$ has been detected in a-IGZO ${ }^{37}$, a significant amount of $\mathrm{OH}$ and $\mathrm{V}_{\mathrm{O}}$-related species are apparent at the top surface of the a-IGZO films presented herein.

After photo-creation of $\mathrm{V}_{\mathrm{O}}$, the oxygen can be accommodated interstitially or through the formation of peroxides, which involve the covalent bonding of two oxygen atoms $(\mathrm{O}-\mathrm{O})$. While interstitial oxygens are stoichiometric defects which act as acceptors ${ }^{34}$, peroxides are donors that spontaneously form when a large concentration of holes is available in the $\mathrm{E}_{\mathrm{V}}{ }^{41}$. The mechanism responsible for the deep UV light instability in a-IGZO is thus summarized diagrammatically in Fig. 7.

Suppression of the light instability. Having identified the backchannel as the source of most of the light instability, owing to the defects that occupy the top surface of the a-IGZO, the effect of applying a back bias to reduce the instability is investigated. Double gate TFT structures with transparent top gates that fully (Fig. 8a) or partially (Fig. 8e) cover the channel region are used in the investigation. A transparent material (IZO) is intentionally used for the top gates to isolate the effect of the electrical back bias from that of light-shielding. Three bias conditions are investigated: (1) Top gate (TG) sweep, where the TG is swept from - 15 to $15 \mathrm{~V}$, while grounding the bottom gate (BG) (see inset of Fig. 8f). (2) BG sweep, where the BG is swept from -15 to $15 \mathrm{~V}$, while grounding the TG (see inset of Fig. 8g). (3) Double gate (DG) sweep, where the TG and BG are shorted and swept from -15 to $15 \mathrm{~V}$ (see inset of Fig. 8h). 


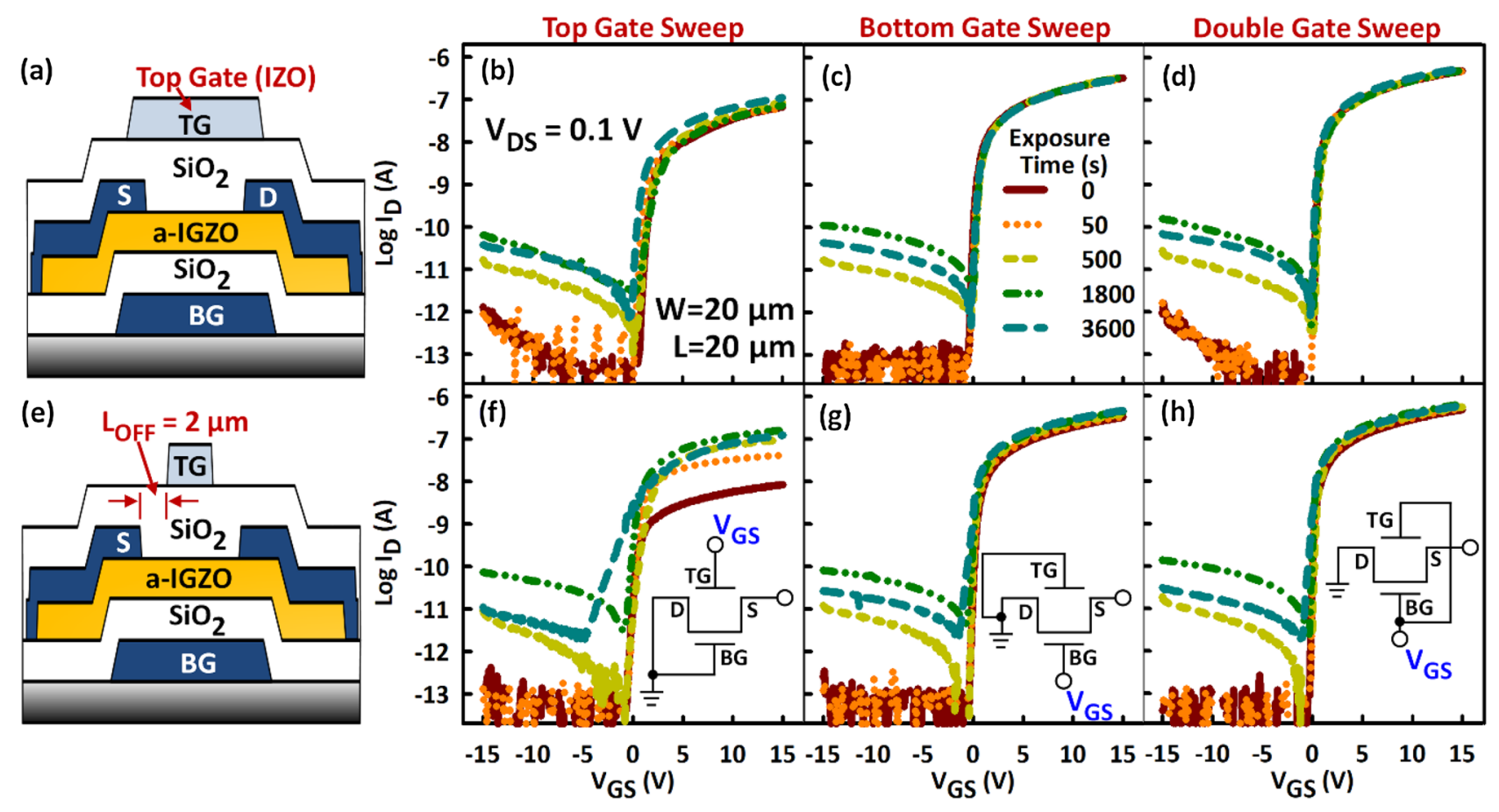

Figure 8. Effect of back bias on deep UV light $(\lambda=172 \mathrm{~nm})$ instability in a-IGZO TFTs. (a and e) Double gate TFT structures used for the investigation with a (a) full and (e) partial back gate (top gate). A transparent top gate (TG) material (IZO) is used to separate the bias from the light-shielding effect. ( $\mathbf{c}$ to $\mathbf{h}$ and $\mathbf{f}$ to $\mathbf{h}$ ) Evolution of transfer characteristics with light exposure time under three bias conditions: (b) and (f) Top gate (TG) sweep, where the TG is swept while grounding the bottom gate as shown by the inset of (f). (c) and (g) BG sweep, where the BG is swept while grounding the TG as shown by the inset of (g). (d) and (h) Double gate (DG) sweep, where TG and BG are shorted as shown by the inset of (h). Grounding or applying a positive back bias after radiation suppresses light instability in a-IGZO TFTs.

Extracted TFT parameters can be found in Supplementary Fig. S5. The DG TFT results are interesting and support the light instability mechanism described above. First, the existence of a full TG bias suppresses the negative $\Delta \mathrm{V}_{\mathrm{TH}}$, for all bias conditions (see Fig. 8b-d and Supplementary Fig. S5a). However, the off-state leakage current $\left(\mathrm{I}_{\mathrm{OFF}}\right)$ significantly increases after UV light radiation (Fig. 8 and Supplementary Fig. S5b). This indicates that $\mathrm{I}_{\mathrm{OFF}}$ is the result of photogenerated holes drifting from the $\mathrm{D}$ to the $\mathrm{S}$. While a grounded or negatively biased TG suppresses electrons from the conductive backchannel, which is the reason for the negligible $\Delta \mathrm{V}_{\mathrm{TH}}$, it promotes hole induction, consistent with the high $\mathrm{I}_{\mathrm{OFF}}$. $\mathrm{I}_{\mathrm{OFF}}$ is also high during the DG sweep (grounded TG) because the hole layer is simply shifted towards the frontchannel, which is negatively biased. Grounding or negatively biasing the TG does not make a big difference with regards to the size of the off-state current because hole induction by $\mathrm{V}_{\mathrm{GS}}$ is difficult in a-IGZO, owing to the large concentration of $\mathrm{V}_{\mathrm{O}}$ located less than $1 \mathrm{eV}$ above $\mathrm{E}_{\mathrm{V}}{ }^{43}$. The holes responsible are the photogenerated holes that are yet to recombine.

Second, negative $\Delta \mathrm{V}_{\mathrm{TH}}$ and increase in SS occur after UV light radiation for $3600 \mathrm{~s}$ when a partial TG is implemented (Fig. $8 \mathrm{f}$ and Supplementary Fig. S5c). However, the negative $\Delta \mathrm{V}_{\mathrm{TH}}$ is not as large as that of a single gate TFT (Fig. 1c), indicating partial suppression of the conductive backchannel electrons by the partial TG. Additionally, the SS increases without the formation of a hump during the TG sweep (Fig. 8f) because there is only one channel (the backchannel) involved, supporting the mechanism for the "hump". However, suppression of the effect of the conductive backchannel electrons can be seen during the BG (Fig. 8g) or DG (Fig. 8h) sweep with a partial TG but evidence of it just starting to appear is apparent. The increase in the on-state current $\left(\mathrm{I}_{\mathrm{ON}}\right)$ after UV light radiation during the TG sweep (Fig. 8f) is consistent with a photoinduced increase in the conductance of the offset regions. Note that the increase in $\mathrm{I}_{\mathrm{ON}}$ after UV light radiation is almost negligible when a full TG is implemented (Supplementary Fig. S5b). Consequently, the change in field-effect mobility after UV light radiation is exceedingly small when a full TG is used (Supplementary Fig. S5d).

These results provide further evidence showing that defects occupying the top surface of the a-IGZO are the source of the light instability in a-IGZO TFTs and that their effect can be suppressed by applying a back bias. This is especially important in applications such as transparent displays where the use of light shields is not possible. Although back biasing does not prevent the off-state currents from increasing, this is not expected to be a problem as they do not exceed $100 \mathrm{pA}$ and they quickly recover at room temperature when the holes recombine. An alternative to applying a back bias, for instance in single gate inverted staggered TFTs (Fig. 1a), would be to reduce the thickness of the a-IGZO film. By doing this, the bottom (front) gate will not only have control of the backchannel, but the total number of defects is also reduced ${ }^{9}$. As shown in Fig. 9, using an a-IGZO film thickness of $7 \mathrm{~nm}$ results in negligible $\Delta \mathrm{V}_{\mathrm{TH}}$. 


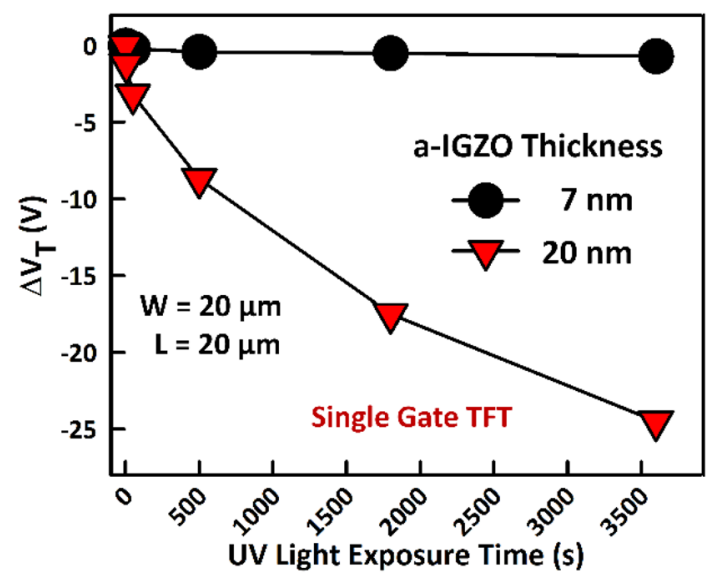

Figure 9. Threshold voltage shift $\left(\Delta \mathrm{V}_{\mathrm{TH}}\right)$ in inverted staggered (single gate) a-IGZO TFTs as a function of deep UV light $(\lambda=172 \mathrm{~nm}$ ) exposure time. Reducing the thickness of the a-IGZO from 20 to $7 \mathrm{~nm}$ almost completely suppresses the deep UV light instability. a-IGZO film thickness reduction enhances the bottom gate control over the back (top) channel and also decreases the total number of defects.

Fabrication process optimization to ensure a clean back interface is thus another way to minimize the light instability. The use of etch-stopper layers ${ }^{51}$, damage-free source/drain metal etchants ${ }^{19}$, high quality encapsulation layers ${ }^{16}$, high temperature or long-time annealing ${ }^{12}$, high pressure or water vapor-assisted annealing ${ }^{17,18}$ and treatments ${ }^{52,53}$, are some of the optimization techniques that can be implemented.

\section{Conclusion}

By radiating a-IGZO TFTs with deep UV light $(\lambda=175 \mathrm{~nm})$, we have shown that the origin of light instability in a-IGZO TFTs is $V_{O}$ and hydrogen-related defects that are located at the top surface of the a-IGZO film. Under light illumination, metastable donor states of these defects are created, making the backchannel conductive. This conductive backchannel results in rigid negative $\Delta \mathrm{V}_{\mathrm{TH}}$ that is accompanied by an increase in SS and a 'hump' in the subthreshold region of the transfer characteristics. Most importantly, we have also shown that this instability to light illumination can be suppressed by applying a back bias or decreasing the thickness of the a-IGZO film in applications, such as transparent displays in Heads Up Displays (HUDs) or smart glasses, where the use of light shields is not permissible. Fabrication process techniques that ensure a clean top surface of the a-IGZO film, such as plasma treatments, water vapor-assisted annealing, and high-quality encapsulation layers are also necessary to minimize the light instability.

\section{Methods}

Device fabrication. We fabricated the a-IGZO TFTs with the inverted staggered structure (Fig. 1a) using the backchannel etch (BCE) process described in detail elsewhere ${ }^{19}$. In this process, molybdenum (Mo) layers deposited by sputtering at $200^{\circ} \mathrm{C}$ are used for the gate $(60 \mathrm{~nm})$ and source/drain $(150 \mathrm{~nm})$ electrodes. Silicon-dioxide $\left(\mathrm{SiO}_{2}\right)$ layers deposited through plasma-enhanced chemical vapor deposition at $360{ }^{\circ} \mathrm{C}$ and $200{ }^{\circ} \mathrm{C}$ are used for the gate-insulator $(200 \mathrm{~nm})$ and the passivation layer $(200 \mathrm{~nm})$, respectively. The $20 \mathrm{~nm}$-thick a-IGZO layer is deposited at $200{ }^{\circ} \mathrm{C}$ by reactive sputtering using a polycrystalline IGZO target $\left(\operatorname{In}_{2} \mathrm{O}_{3}: \mathrm{Ga}_{2} \mathrm{O}_{3}: \mathrm{ZnO}=1: 1: 1 \mathrm{~mol} \%\right)$. The gate-insulator (G.I.) and the a-IGZO layer are deposited consecutively in a cluster deposition tool, without breaking vacuum, to achieve a clean G.I./a-IGZO interface. A hydrogen peroxide-based etchant $(\mathrm{pH}=\sim 5)$ is used to pattern the source/drain electrodes to minimize backchannel acid corrosion ${ }^{19}$, and to ensure a reproducible unstressed state, the devices are annealed at $250{ }^{\circ} \mathrm{C}$ in vacuum for $2 \mathrm{~h}$ before measuring.

Characterization. We used the Agilent 4156C precision semiconductor parameter analyzer and the Agilent E4980A Precision LCR meter to measure the current-voltage (I-V) and capacitance-voltage $(\mathrm{C}-\mathrm{V})$ characteristics, respectively. For the $\mathrm{C}-\mathrm{V}$ measurement, we superimposed the $\mathrm{DC}$ gate-voltage $\left(\mathrm{V}_{\mathrm{GS}}\right)$ on a small $\mathrm{AC}$ signal $(0.1 \mathrm{~V})$ of frequency $1 \mathrm{kHz}$, while keeping the source and drain shorted. We derived the field-effect mobility $\left(\mu_{\mathrm{FE}}\right)$ in the linear regime (with drain voltage $\left.\left(\mathrm{V}_{\mathrm{DS}}\right)=0.1 \mathrm{~V}\right)$ from the transconductance $\left(\mathrm{gm}=\partial \mathrm{I}_{\mathrm{D}} / \partial \mathrm{V}_{\mathrm{GS}}\right)$ by using $\mu_{\mathrm{FE}}=\left(\mathrm{gm}^{\star} \mathrm{L}\right) /\left(\mathrm{W}^{\star} \mathrm{C}_{\mathrm{OX}}{ }^{\star} \mathrm{V}_{\mathrm{DS}}\right)$. Here, $\mathrm{I}_{\mathrm{D}}, \mathrm{C}_{\mathrm{OX}}$, $\mathrm{L}$, and $\mathrm{W}$ are the drain terminal current, the G.I. capacitance per unit area, the channel length, and the channel width, respectively. We took the SS as the minimum value of $\left(\partial \log \left(\mathrm{I}_{\mathrm{D}}\right) / \partial \mathrm{V}_{\mathrm{GS}}\right)^{-1}$ and the threshold voltage $\left(\mathrm{V}_{\mathrm{TH}}\right)$ as the $\mathrm{V}_{\mathrm{GS}}$ corresponding to $\mathrm{I}_{\mathrm{D}}$ of $1 \mathrm{nA}$. We carried out the light illumination experiments at room temperature with the TFT electrodes in the floating state. To further characterize the effects of deep UV light radiation, we extracted flat band parameters by a combined analysis of the TFT transfer $\left(\mathrm{I}_{\mathrm{D}}-\mathrm{V}_{\mathrm{GS}}\right)$ and $\mathrm{C}-\mathrm{V}$ characteristics according to methods previously described in ${ }^{20}$. We characterized thin film stacks of $\mathrm{SiO}_{2}(100 \mathrm{~nm}) / \mathrm{a}-\mathrm{IGZO}(20 \mathrm{~nm}) / \mathrm{SiO}_{2}(100 \mathrm{~nm})$ by using Time-of-Flight Secondary Ion Mass Spectrometry (ToF-SIMS) and X-ray photoelectron spectroscopy (XPS) depth profiles. For ToF-SIMS, an ION-TOF (Münster, Germany) instrument (TOF-SIMS V) equipped with a Bi1 + (30 keV, $1 \mathrm{pA})$ and Cs + $(3 \mathrm{keV}$, $30 \mathrm{nA}$ ) gun is used and raster areas for sputter and analysis are $200 \mu \mathrm{m} \times 200 \mu \mathrm{m}$ and $50 \mu \mathrm{m} \times 50 \mu \mathrm{m}$, respectively. 


\section{Data availability}

The authors confirm that all the data supporting the findings of this study are available within the article [and/ or] its supplementary materials.

Received: 4 May 2021; Accepted: 6 July 2021

Published online: 16 July 2021

\section{References}

1. Street, R. A. Thin-film transistors. Adv. Mater. 21, 2007-2022 (2009).

2. Snell, A. J., Mackenzie, K. D., Spear, W. E., LeComber, P. G. \& Hughes, A. J. Application of amorphous silicon field effect transistors in addressable liquid crystal display panels. Appl. Phys. A Mater. Sci. Process. 24, 357-362 (1981).

3. Kuo, Y. Thin film transistor technology-past, present, and future. Electrochem. Soc. Interface 22, 55-61 (2013).

4. Nomura, K. et al. Room-temperature fabrication of transparent flexible thin-film transistors using amorphous oxide semiconductors. Nature 432, 488-492 (2004).

5. Kwon, J.-Y., Lee, D.-J. \& Kim, K.-B. Review paper: Transparent amorphous oxide semiconductor thin film transistor. Electron. Mater. Lett. 7, 1-11 (2011).

6. Nomura, K., Kamiya, T. \& Hosono, H. Interface and bulk effects for bias-light-illumination instability in amorphous-In-Ga-Zn-O thin-film transistors. J. Soc. Inf. Disp. 18, 789 (2010).

7. Oh, H. et al. Photon-accelerated negative bias instability involving subgap states creation in amorphous In-Ga-Zn-O thin film transistor. Appl. Phys. Lett. 9, 183502 (2010).

8. Migliorato, P., Delwar Hossain Chowdhury, M., GwangUm, J., Seok, M. \& Jang, J. Light/negative bias stress instabilities in indium gallium zinc oxide thin film transistors explained by creation of a double donor. Appl. Phys. Lett. 101, 123502 (2012).

9. Mativenga, M., Um, J. \& Jang, J. Reduction of bias and light instability of mixed oxide thin-film transistors. Appl. Sci. (Basel) 7, 885 (2017).

10. Ryu, B., Noh, H.-K., Choi, E.-A. \& Chang, K. J. O-vacancy as the origin of negative bias illumination stress instability in amorphous In-Ga-Zn-O thin film transistors. Appl. Phys. Lett. 97, 022108 (2010).

11. Oh, H. et al. Transition of dominant instability mechanism depending on negative gate bias under illumination in amorphous In-Ga-Zn-O thin film transistor. Appl. Phys. Lett. 98, 033504 (2011).

12. Chowdhury, M. D. H., Ryu, S. H., Migliorato, P. \& Jang, J. Effect of annealing time on bias stress and light-induced instabilities in amorphous indium-gallium-zinc-oxide thin-film transistors. J. Appl. Phys. 110, 114503 (2011).

13. Migliorato, P. \& Jang, J. Bias and light-induced instabilities in a-IGZO thin film transistors. Handbook of Visual Display Technology 1017-1050 (Springer International Publishing, 2016).

14. Flewitt, A. J. \& Powell, M. J. A thermalization energy analysis of the threshold voltage shift in amorphous indium gallium zinc oxide thin film transistors under simultaneous negative gate bias and illumination. J. Appl. Phys. 115, 134501 (2014).

15. Ueoka, Y. et al. Density of states in amorphous in-Ga-Zn-O thin-film transistor under negative bias illumination stress. ECS J. Solid State Sci. Technol. 3, Q3001-Q3004 (2014).

16. Nomura, K., Kamiya, T. \& Hosono, H. Highly stable amorphous In-Ga-Zn-O thin-film transistors produced by eliminating deep subgap defects. Appl. Phys. Lett. 99, 053505 (2011).

17. Ji, K. H. et al. Effect of high-pressure oxygen annealing on negative bias illumination stress-induced instability of InGaZnO thin film transistors. Appl. Phys. Lett. 98, 103509 (2011).

18. Ahn, B. D., Kim, H.-S., Yun, D.-J., Park, J.-S. \& Kim, H. J. Improvement of negative bias temperature illumination stability of amorphous IGZO thin-film transistors by water vapor-assisted high-pressure oxygen annealing. ECS J. Solid State Sci. Technol. 3, Q95-Q98 (2014).

19. Park, Y. C., Um, J. G., Mativenga, M. \& Jang, J. Modification of electrode-etchant for sidewall profile control and reduced backchannel corrosion of inverted-staggered metal-oxide TFTs. ECS J. Solid State Sci. Technol. 4, Q124-Q129 (2015).

20. Migliorato, P. et al. Characterization and modeling of a-IGZO TFTs. J. Display Technol. 11, 497-505 (2015).

21. Son, K.-S. et al. Highly stable double-gate Ga-in-Zn-O thin-film transistor. IEEE Electron Device Lett. 31, 812-814 (2010).

22. Huang, X. et al. Electrical instability of amorphous indium-gallium-zinc oxide thin film transistors under monochromatic light illumination. Appl. Phys. Lett. 100, 243505 (2012).

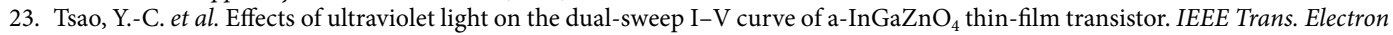
Devices 66, 1772-1777 (2019).

24. Chowdhury, M. D. H., Migliorato, P. \& Jang, J. Light induced instabilities in amorphous indium-gallium-zinc-oxide thin-film transistors. Appl. Phys. Lett. 97, 173506 (2010).

25. Chowdhury, M. D. H., Migliorato, P. \& Jang, J. Temperature dependence of negative bias under illumination stress and recovery in amorphous indium gallium zinc oxide thin film transistors. Appl. Phys. Lett. 102, 143506 (2013).

26. Thompson, A. C. \& Vaughan, D. X-Ray Data Booklet. (Lawrence Berkeley National Laboratory, 2001).

27. Ueoka, Y. et al. Analysis of electronic structure of amorphous $\mathrm{InGaZnO} / \mathrm{SiO}_{2}$ interface by angle-resolved X-ray photoelectron spectroscopy. J. Appl. Phys. 114, 163713 (2013).

28. Nomura, K. et al. Depth analysis of subgap electronic states in amorphous oxide semiconductor, a-In-Ga-Zn-O, studied by hard X-ray photoelectron spectroscopy. J. Appl. Phys. 109, 073726 (2011).

29. Vlasenko, L. S. \& Watkins, G. D. Optical detection of electron paramagnetic resonance in room-temperature electron-irradiated ZnO. Phys. Rev. B Condens. Matter Mater. Phys. 71, 125210 (2005).

30. Laiho, R., Vlasenko, L. S. \& Vlasenko, M. P. Optical detection of magnetic resonance and electron paramagnetic resonance study of the oxygen vacancy and lead donors in ZnO. J. Appl. Phys. 103, 123709 (2008).

31. Lany, S. \& Zunger, A. Anion vacancies as a source of persistent photoconductivity in II-VI and chalcopyrite semiconductors. Phys. Rev. B Condens. Matter Mater. Phys. 72, 035215 (2005).

32. Janotti, A. \& Van de Walle, C. G. Native point defects in ZnO. Phys. Rev. B Condens. Matter Mater. Phys. 76, 165202 (2007).

33. Clark, S. J., Robertson, J., Lany, S. \& Zunger, A. Intrinsic defects in ZnO calculated by screened exchange and hybrid density functionals. Phys. Rev. B Condens. Matter Mater. Phys. 81, 115311 (2010).

34. Lee, W.-J., Ryu, B. \& Chang, K. J. Electronic structure of oxygen vacancy in crystalline InGaO3(ZnO)m. Physica B Condens. Matter 404, 4794-4796 (2009)

35. Janotti, A. \& Van de Walle, C. G. Fundamentals of zinc oxide as a semiconductor. Rep. Prog. Phys. 72, 126501 (2009).

36. Kamiya, T., Nomura, K. \& Hosono, H. Present status of amorphous In-Ga-Zn-O thin-film transistors. Sci. Technol. Adv. Mater. 11, 044305 (2010).

37. Nomura, K., Kamiya, T. \& Hosono, H. Effects of diffusion of hydrogen and oxygen on electrical properties of amorphous oxide semiconductor, In-Ga-Zn-O. ECS J. Solid State Sci. Technol. 2, P5-P8 (2013).

38. Kim, H. et al. Role of incorporated hydrogen on performance and photo-bias instability of indium gallium zinc oxide thin film transistors. J. Phys. D Appl. Phys. 46, 055104 (2013). 
39. Noh, H.-K., Park, J.-S. \& Chang, K. J. Effect of hydrogen incorporation on the negative bias illumination stress instability in amorphous In-Ga-Zn-O thin-film-transistors. J. Appl. Phys. 113, 063712 (2013).

40. de Jamblinne de Meux, A., Pourtois, G., Genoe, J. \& Heremans, P. Defects in amorphous semiconductors: The case of amorphous indium gallium zinc oxide. Phys. Rev. Applied. 9, 054039 (2018).

41. Lany, S. \& Zunger, A. Comment on "Intrinsic n-type behavior in transparent conducting oxides: A comparative hybrid-functional study of $\mathrm{In}_{2} \mathrm{O}_{3}, \mathrm{SnO}_{2}$, and $\mathrm{ZnO}$." Phys. Rev. Lett. 103, 069601 (2011).

42. Mativenga, M., Jun, H., Choe, Y., Um, J. G. \& Jang, J. Circular structure for high mechanical bending stability of a-IGZO TFTs. IEEE J. Electron Devices Soc. 5, 453-457 (2017).

43. Nomura, K. et al. Subgap states in transparent amorphous oxide semiconductor, In-Ga-Zn-O, observed by bulk sensitive x-ray photoelectron spectroscopy. Appl. Phys. Lett. 92, 202117 (2008).

44. Chen, T.-C., Kuo, Y., Chang, T.-C., Chen, M.-C. \& Chen, H.-M. Mechanism of a-IGZO TFT device deterioration-illumination light wavelength and substrate temperature effects. J. Phys. D Appl. Phys. 50, 42LT02 (2017).

45. Billah, M. M., Chowdhury, M. D. H., Mativenga, M., Um, J. G., Mruthynjaya, R. K., Heiler, G. N., Tredwell, T. J., \& Jang, J. Analysis of improved performance under negative bias illumination stress of dual gate driving a- IGZO TFT by TCAD simulation. IEEE Electron Device Lett. 37, 735-738 (2016).

46. Zan, H.-W. et al. Low temperature annealing with solid-state laser or UV lamp irradiation on amorphous IGZO thin-film transistors. Electrochem. Solid State Lett. 13, H144 (2010).

47. Lee, D. H. et al. Steady-state photoconductivity of amorphous In-Ga-Zn-O. Thin Solid Films 518, 3000-3003 (2010).

48. Noh, H.-K., Chang, K. J., Ryu, B. \& Lee, W.-J. Electronic structure of oxygen-vacancy defects in amorphous In-Ga-Zn-O semiconductors. Phys. Rev. B Condens. Matter Mater. Phys. 84, 115205 (2011).

49. Staebler, D. L. \& Wronski, C. R. Optically induced conductivity changes in discharge-produced hydrogenated amorphous silicon. J. Appl. Phys. 51, 3262-3268 (1980).

50. Stutzmann, M., Jackson, W. B. \& Tsai, C. C. Light-induced metastable defects in hydrogenated amorphous silicon: A systematic study. Phys. Rev. B Condens. Matter 32, 23-47 (1985).

51. Mativenga, M., Choi, J. W., Hur, J. H., Kim, H. J. \& Jang, J. Highly stable amorphous indium-gallium-zinc-oxide thin-film transistor using an etch-stopper and a via-hole structure. J. Inf. Disp. 12, 47-50 (2011).

52. Chang, G.-W. et al. Suppress temperature instability of InGaZnO thin film transistors by $\mathrm{N}_{2} \mathrm{O}$ plasma treatment, including thermalinduced hole trapping phenomenon under gate bias stress. Appl. Phys. Lett. 100, 182103 (2012).

53. Yamazaki, H. et al. The influence of fluorinated silicon nitride gate insulator on positive bias stability toward highly reliable amorphous InGaZnO thin-film transistors. ECS J. Solid State Sci. Technol. 3, Q20-Q23 (2014).

\title{
Acknowledgements
}

M. Mativenga thanks Prof. Jin Jang for his help in fabricating the a-IGZO TFTs used in this study. This work was supported in part by the National Research Foundation of South Korea (NRF) through the Korean Government Ministry of Science, ICP and Future Planning (MSIP) under Grant NRF-2019R1F1A1059601 and in part by NRF funded by the Ministry of Science and ICT under the Brainpool (BP) Grant NRF-2019H1D3A1A02070322.

\section{Author contributions}

M. M. and U. J. G. conceived and conducted the experiment(s). M. M. and U. J. G. performed the characterizations of films and devices. M. M. analyzed the data and wrote the paper. M. M. and H. F. performed statistical analysis and figure generation. B. M. M. analyzed the data and conducted TCAD simulation. All authors discussed the results and commented on the manuscript.

\section{Competing interests}

The authors declare no competing interests.

Additional information

Supplementary Information The online version contains supplementary material available at https://doi.org/ 10.1038/s41598-021-94078-8.

Correspondence and requests for materials should be addressed to M.M.

Reprints and permissions information is available at www.nature.com/reprints.

Publisher's note Springer Nature remains neutral with regard to jurisdictional claims in published maps and institutional affiliations.

\begin{abstract}
Open Access This article is licensed under a Creative Commons Attribution 4.0 International License, which permits use, sharing, adaptation, distribution and reproduction in any medium or format, as long as you give appropriate credit to the original author(s) and the source, provide a link to the Creative Commons licence, and indicate if changes were made. The images or other third party material in this article are included in the article's Creative Commons licence, unless indicated otherwise in a credit line to the material. If material is not included in the article's Creative Commons licence and your intended use is not permitted by statutory regulation or exceeds the permitted use, you will need to obtain permission directly from the copyright holder. To view a copy of this licence, visit http://creativecommons.org/licenses/by/4.0/.
\end{abstract}

(c) The Author(s) 2021 